Clemson University

TigerPrints

Presentations

University Libraries

$6-30-2020$

Copyright Considerations

John Morgenstern

Follow this and additional works at: https://tigerprints.clemson.edu/lib_pres

Part of the Scholarly Publishing Commons 


\section{COPYRIGHT CONSIDERATIONS}

- How to find open-source videos, illustrations

- Model scenarios for copyright use 
$\Delta$

COPY
\& PUBLISH
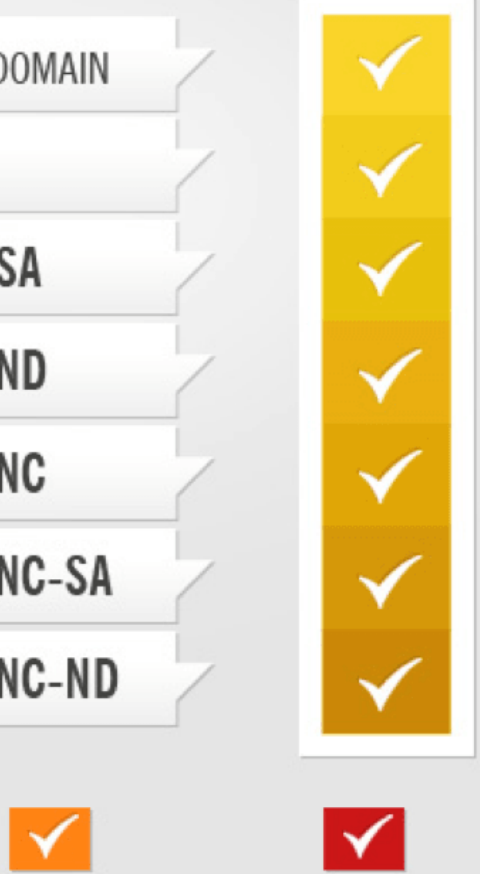

You can redistribute (copy, publish, display, communicate, etc.)
PUBLIC DOMAIN

CC BY

(i)(2) CC BY-SA

(1) $\Theta \quad C C B Y-N D$

(i) $(5) \quad \mathrm{CCBY}-\mathrm{NC}$

(†) (ㅇ) CC BY-NC-SA

(i) $\odot$ CC BY-NC-ND

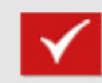
commercially

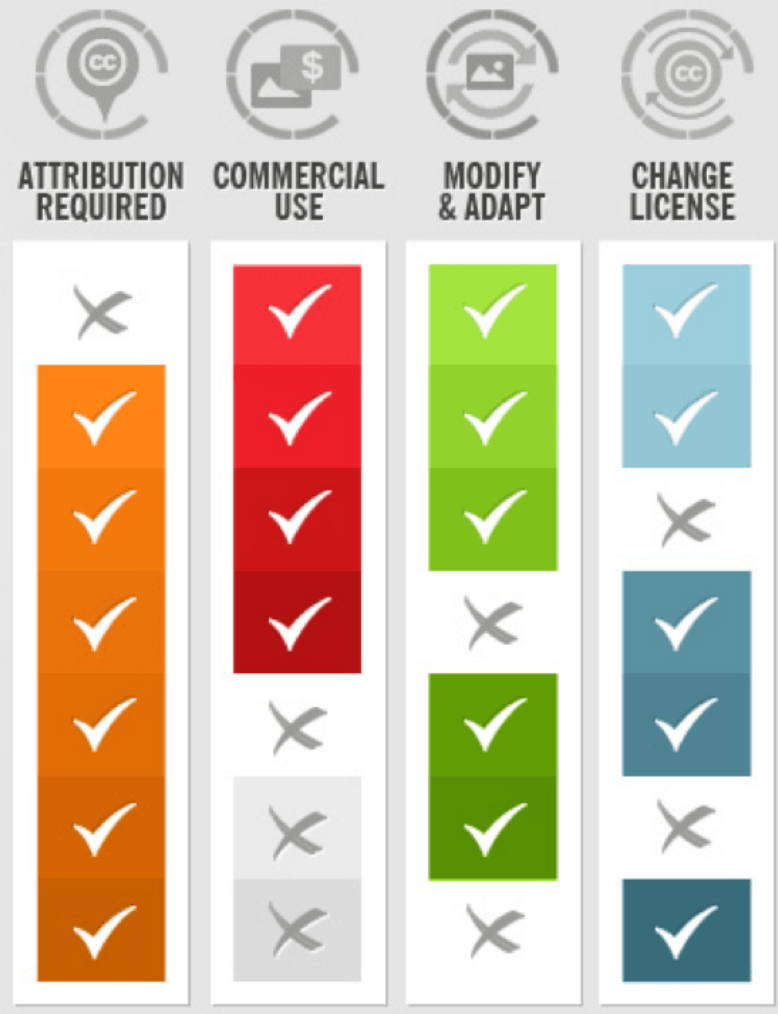

You can use the work

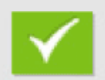

You can modify and adapt the original work

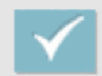

You can choose license type for your adaptations

A Creative Commons license is one of several public copyright licenses that allow authors to stipulate acceptable uses for their work.

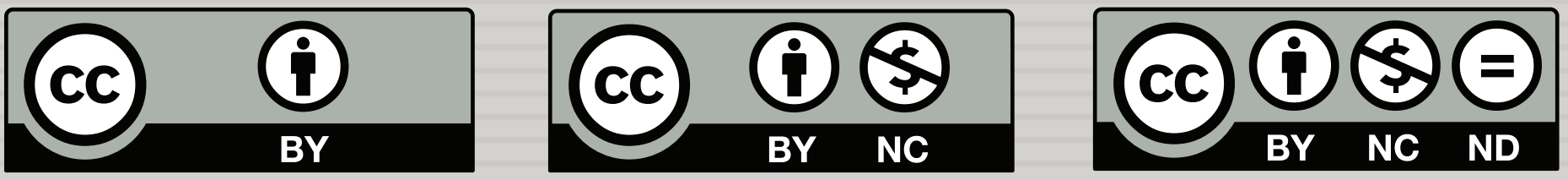

https://creativecommons.org/licenses 


\section{Where do I find open-source material?}

Open source

images and

videos are

either in the

public domain

or shared under

Creative

Commons

licenses,

allowing others

to use the

content without

fear of

infringement. $\square$ The advance search settings for many following databases will filter for openlicensed images and videos, including Google images, YouTube, and Flickr.

$\square$ Wikipedia Commons

$\square$ Open Culture: http://www.openculture.com

$\square$ Additional resources and links are available on the Libraries guide to Open Education Resources (OERs): https://clemson.libguides.com/open 


\section{Scenario 1}

Extension agencies often recycle/share materials. Can I use an illustration (line drawing, photograph, etc.) published by another state's Extension agency in materials for a course I'm developing? Is this covered by the TEACH Act? 


\section{Scenario 1: reflection}

$\square$ We recommend that you reach out to colleagues in that state's Extension agency to ask for permission if you intend to publish the material or distribute it to a class online (even on Canvas).

$\square$ An email specifying your particular use and granting permission will suffice.

$\square$ The TEACH Act doesn't cover online distribution, even on Canvas. 


\section{Scenario 2}

The course l'm developing requires students to learn a set of facts/information. This information's already available online from the state. Can I cut and paste from their website? Can I reproduce a chart/graph that conveys this information? 


\section{Scenario 2: reflection}

$\square$ You can't reproduce text from a website, textbook, or other source, but you can rephrase the same information in your own words

$\square$ You can't reproduce a chart/graph, but you can create your own chart/graph using the same data

$\square$ You may be able to reproduce Federal documents/websites with the appropriate attribution 


\section{Scenario 3}

I took photos in the SCBG and in the Experimental Forest, and l'd like to use the images in a publication. How do I retain copyright on the photos? If I took the photos as part of my job or while on the clock, does the University own the copyright as work product? Can I make them available to other Extension agents to use freely in their publications? 


\section{Scenario 3: reflection}

$\square$ You own the copyright on your original photos unless you designate it to a publisher or unless the designation of copyright is a condition of your employment (e.g. a photographer hired by the University, some media specialists, etc.). See the University's Intellectual Property Policy for details: http://media.clemson.edu/research/technologytransfer/ip-policy.pdf.

$\square$ If you wish to include the image in a scholarly publication, ask your publisher if you can license the images for use rather than designate your copyright.

$\square$ If you wish to share the photos for others to use freely, we recommend publishing them under a Create Commons License. 


\section{Scenario 4}

I found the perfect illustration online, but I can't locate the copyright holder. Is it permissible to use the image anyway, if I've done my due diligence? 


\section{Scenario 4: reflection}

$\square$ While historical images with no known author may be considered public domain, there's significant risk of infringement in reproducing images that you find online even if you can't identify the copyright holder.

$\square$ There are many open-source images available for use-choose one of them and eliminate risk. 


\section{Scenario 5}

A student put together a presentation for a course that was so great that l'd like to incorporate it into future courses and/or in a publication. Am I allowed to use the student's work without permission since it was done for a class? What permission do I need? Is there a form available that students can sign to license the presentation for my desired use? 


\section{Scenario 5: reflection}

$\square$ You may use student work, provided that you have their written permission.

$\square \quad$ The permission can be a simple, signed statement:

I hereby grant permission for Clemson University Press to use/publish any and all work undertaken in [course name] during the [season year] semester in all formats including, for the sake of clarity, social media and digital publications. I understand that due acknowledgment will be given only where deemed appropriate by [instructor's name].

Student name (please print clearly):

Student signature:

Date: 